\title{
Policy Strategies for the "New Normal" in Healthcare to Ensure Access to High-Quality Cancer Care
}

Alyssa A. Schatz, MSWa; Katy Winckworth Prejsnar, MPHª; James McCanney, JDa; Meghan Gutierrez; Stefanie Johoc; Joseph Alvarnas, MDd; and Robert W. Carlson, MDa

\begin{abstract}
In recent years, oncology has seen a rapid increase in the introduction of high-cost innovative therapies while scrutiny around drug pricing has simultaneously amplified. Significant policy shifts impacting health coverage and benefit design are also being implemented, including narrow network health plans, uncertainty around the Affordable Care Act insurance exchanges, and threats to preexisting condition protections. Shifting health coverage policy combined with high drug prices and outdated reimbursement systems may create barriers to patient access to innovation and high-quality cancer care. To understand how trends in health policy are impacting the oncology ecosystem, NCCN convened the NCCN Policy Summit: Policy Strategies for the "New Normal" in Healthcare to Ensure Access to High-Quality Cancer Care on June 25, 2018. The summit included discussion of how innovation is changing cancer treatment, care delivery, and ways health systems are responding; the impact of narrow networks on access to academic cancer centers; and how the evolving health policy landscape is affecting access to highquality cancer care for patients.
\end{abstract}

J Natl Compr Canc Netw 2019;17(2):105-109 doi: 10.6004/jnccn.2018.7267

aNational Comprehensive Cancer Network, Plymouth Meeting, Pennsylvania; ${ }^{b}$ City of Hope Comprehensive Cancer Center, Duarte, California; 'Research/ Patient advocate, and consultant, Philadelphia, Pennsylvania; and 'Lymphoma Research Foundation, New York, New York.

\section{Executive Summary}

Shifting health coverage and reimbursement policy combined with the emergence of promising novel treatments for cancer is transforming the oncology landscape and poses significant implications for patient access to high-quality cancer care. To understand how shifting trends in health policy are impacting the oncology ecosystem, NCCN convened the NCCN Policy Summit: Policy Strategies for the "New Normal" in Healthcare to Ensure Access to High-Quality Cancer Care on June 25, 2018. A diverse group of stakeholders gathered to discuss how innovation is changing cancer treatment, care delivery, and ways health systems are responding; the impact of narrow networks on access to academic cancer centers; and how the evolving health policy landscape is affecting access to affordable, high-quality cancer care for patients (see supplemental eAppendix 1 for a list of participating speakers and panelists).

\section{Accelerating Access to Innovation}

The FDA, under the leadership of Commissioner Scott Gottlieb, recently introduced policies intended to accelerate approval of novel therapies, which has been particularly impactful in oncology. Commissioner Gottlieb joined NCCN at the June 2018 NCCN Policy Summit to discuss actions the FDA is taking to accelerate access to innovation.

In response to advances in precision medicine, the FDA is considering new models to modernize how clinical trials are designed and evaluated in the approval process. In particular, the FDA is exploring the use of seamless drug development programs for enriched phase I cohorts. ${ }^{1}$ Enriched cohorts are selected for a treatment based on how their tumor expresses a biomarker. ${ }^{1}$ Under a seamless drug development program, the FDA allows drug developers to quickly expand enriched phase I cohorts and evaluate the drug in one continuous clinical trial rather than starting and stopping drug development in each phase of a 3-phase clinical trial. ${ }^{1}$

See JNCCN.org for supplemental online content. 
In addition to revisiting the design of clinical trials, the FDA is considering significant changes to primary clinical end points used in trials. ${ }^{1}$ Overall survival has traditionally acted as the primary clinical end point when the FDA considers approval of drugs. Decades ago, anticancer drugs were highly toxic with only modest efficacy, and therefore overall survival was often the only end point used to justify the approval of a treatment. ${ }^{1}$ However, novel therapies offering reduced toxicity and enhanced efficacy are pressing the FDA to reconsider meaningful end points. After consultation with patient advocacy groups, cancer researchers, and the Oncologic Drugs Advisory Committee, Commissioner Gottlieb announced the FDA will consider additional end points, including progression-free survival and objective response rate. ${ }^{1}$ To improve transparency, the Center for Drug Evaluation and Research will make publicly available on the internet a list of surrogate end points that are the primary basis of approval or licensure of a drug or biologic for both accelerated and traditional approvals. ${ }^{1}$

Following the approval of a drug or biologic, the FDA is working to improve the collection of postmarket data and real-world evidence. The FDA requested \$23 million in the fiscal year 2019 budget to establish a new medical data enterprise for real-world data and advanced analytics. ${ }^{1}$ If approved, this funding will give the FDA the ability to conduct near-real-time evidence evaluation down to the level of individual electronic health records for at least 10 million individuals. ${ }^{1}$

Commissioner Gottlieb emphasized that the robust collection of postmarket data and real-world evidence is an endeavor that cannot be accomplished alone, and is calling on private payers to collaborate with the FDA. Under this arrangement, Commissioner Gottlieb envisions that the FDA will provide information on the efficacy, safety, and costeffectiveness of a drug or medical product to facilitate contracting based on the value delivered by new products. ${ }^{1}$ In return, payers can work to improve their sharing of data to improve real-world evidence collection for postmarket analysis of outcomes, such as adverse events associated with targeted drugs. ${ }^{1}$ The sharing of data may allow payers to better relate prices to value, including reductions in hospitalizations or other outcomes relating to cost of care. ${ }^{1}$

\section{Paying for Innovation}

The FDA's efforts to accelerate innovation have had marked effects in oncology, as innovation continues to drive improvements in outcomes for patients with cancer. ${ }^{2}$ Treatments like CAR T-cell therapy are bringing hope to patients who had previously exhausted all other treatment options. Emerging diagnostics can identify patients who will not respond to chemotherapy and therefore can avoid taxing and unnecessary treatments. ${ }^{3}$ However, the high costs associated with these novel therapies and diagnostics pose challenges to patients, providers, and payers. The NCCN
Policy Summit convened a multistakeholder panel of experts to discuss the current challenges and opportunities associated with paying for innovation.

High-cost novel therapies are pressing payers and industry to rethink reimbursement systems that are not designed to accommodate novel therapies with high onetime costs. As the health system shifts to value-based payment models, several private and public payers, in partnership with industry, have begun exploring valuebased payment arrangements as a solution to outdated reimbursement systems. Unfortunately, these value-based payment arrangements for drug pricing have not yet been meaningfully realized in oncology. Several regulatory barriers exist that may impede attempts at value-based pricing frameworks, including the Medicaid best price policy and the federal Anti-Kickback Statute. ${ }^{4}$ Successful implementation of a value-based pricing system will require developing and adopting meaningful and realistic value metrics, establishing what constitutes a reasonable financial reward for value, and addressing regulatory barriers. ${ }^{5}$ Multistakeholder collaboration will be required to achieve a value-based pricing system for oncologic drugs.

Value-based payment models like the Oncology Care Model (OCM) are designed to improve the effectiveness and efficiency of specialty care. These models encourage participating practices to improve care and lower costs through an episode-based payment model, and financially incentivize high-quality, coordinated care. The OCM may have an effect on access to innovation for patients. Unlike fee-for-service payment models, this model encourages heightened value consciousness in therapy selection on the part of the prescribing physician. In response to concerns that value-based payment models may disincentivize the use of high-cost novel therapies, the OCM has implemented 2 policies to accommodate new technologies: the "trend factor" and the "novel therapy adjustment." ${ }^{5}$ Under the trend factor, the Center for Medicare \& Medicaid Innovation (CMMI) within the Centers for Medicare \& Medicaid Services (CMS) will increase their own benchmark prices after studying all of the risk adjustments that occur outside of OCM. The novel therapy adjustment allows practices that see a high number of patients receiving novel therapies to have their rates adjusted to $80 \%$ of actual price. ${ }^{6}$ Additionally, CMMI notes that CAR T-cell therapy will not be considered part of the total cost of care for the purposes of performance-based payments. ${ }^{5}$

As innovations come to market, some new therapies undergo a National Coverage Analysis, a process used by CMS to determine whether the therapy will be nationally covered; any requirements for coverage, including clinical environment, training, and accreditation; and the eligible patient population. ${ }^{6}$ A National Coverage Determination (NCD) is completed following a lengthy, 
often yearlong analysis, and supersedes any local coverage determinations. ${ }^{7}$ An NCD may result in a determination of no coverage, coverage, or coverage with evidence development (CED). A CED may determine coverage of an item or service only in the context of a clinical study and typically requires providers to submit data to receive reimbursement. ${ }^{7}$ Stephanie Farnia of the American Society for Blood and Marrow Transplantation noted that additional processes and paperwork requirements, compounded with the already rigorous FDA approval process, can be frustrating to providers. ${ }^{8}$

In addition to cost and reimbursement hurdles, some novel therapies are accompanied by significant toxicities, which are often service-intensive and expensive to manage. The culmination of expensive drugs and intensive ancillary services to manage adverse events may pose additional cost-sharing requirements for patients. The Lymphoma Research Foundation (LRF) has conducted patient surveys regarding treatment decision-making and analyzes requests submitted to its Lymphoma Helpline. ${ }^{8}$ According to the most recent LRF analysis, high drug costs are an area of increasing importance for patients, with $25 \%$ of respondents reporting that financial toxicity or economic burden was a primary component of treatment decision-making. ${ }^{9}$

Clinical trials play a critical role in ensuring patient access to innovation, but only $5 \%$ of adult patients participate in a clinical trial. ${ }^{10}$ Stefanie Joho is a cancer survivor turned patient and research advocate who has become active as a public speaker and a consultant to the oncologic community. In 2013, Ms. Joho was diagnosed with stage IIB colon cancer. By 2014, the cancer had progressed to stage IV inoperable metastatic disease and at the age of 24 years, Ms. Joho had exhausted all available treatment options. ${ }^{10}$ Thanks to the research efforts of Ms. Joho's younger sister, Ms. Joho enrolled in a clinical trial using immunotherapy with checkpoint inhibitors, and is alive today with no evidence of disease. ${ }^{11}$ Ms. Joho noted that destigmatizing clinical trials and educating the public regarding the potential benefits of participation are powerful means of maximizing treatment options. In addition, it is her belief that effective communication between patients and physicians is key to ensuring access to innovation in cancer treatment. ${ }^{10}$

\section{Narrow Network Implications for Access to High-Quality Cancer Care}

Health plans offered on the Affordable Care Act (ACA) insurance exchanges include many protections for patients with cancer, but are increasingly using narrow networks and tiered network plan designs as a way to reduce premiums. Consumers buying benefits in the exchanges may opt for narrow health plans with reduced access to the higher-quality providers in exchange for lower premiums. Unfortunately, for patients with cancer, this tradeoff may result in added financial and geographic burdens of out-of-network care. ${ }^{12}$ In January 2018, NCCN and Avalere Health collaborated to survey cancer centers designated by the NCI to further understand cancer centers' participation in the 2017 and 2018 exchange marketplace. ${ }^{13}$ In total, 29 cancer centers completed the survey across 21 states and the District of Columbia.

The NCCN survey found that most cancer centers (93\%) are out-of-network for some or all of the health exchange carriers in their state. ${ }^{14}$ In addition to narrow networks, some plans use tiered networks that implement higher or lower cost-sharing to influence where patients seek care. In 2017, more than half of the respondents (54\%) reported that their respective state has tiered provider networks. Of the respondents who were able to indicate their specific tier placement, more than half were in tier 2 or 3, which would result in high enrollee cost-sharing. Under narrow and tiered networks, patients may incur higher out-of-pocket costs to access out-of-network care, or, alternatively, may reduce or delay necessary treatment. ${ }^{15,16}$

According to the National Cancer Database, $>250,000$ Americans traveled $>40$ miles for cancer care in 2015. ${ }^{17}$ Of centers responding to the NCCN survey, $52 \%$ noted they were out-of-network for all out-of-state plans, $26 \%$ were in-network for some bordering-state exchange plans, and none indicated that they were in-network for all exchange plans from bordering states. This may pose implications for patients with cancer who are more likely to travel for care.

The survey results indicate ongoing marketplace challenges, including network variance across regions, high enrollee cost-sharing under tiered networks, and network inclusion barriers for out-of-state patients. Moving forward, greater transparency of health plan design is necessary, as well as consumer education and navigation around exchange network configuration. ${ }^{18}$

\section{Evolving Healthcare Landscape and Implications for Access to High-Quality Cancer Care}

Healthcare reform efforts and shifting federal and state priorities have significant implications for access to highquality and effective care for patients with cancer. Protections under the ACA, value-based payment models, and innovative therapies all offer the potential to improve the overall quality of care for patients. Conversely, shifting federal and state policies regarding insurance coverage and implementation hurdles under value-based care could create additional access barriers and disparate health outcome for patients. The NCCN Policy Summit convened a multistakeholder panel of experts to discuss the current challenges and opportunities in ensuring patients' 
access to affordable, high-quality cancer care within the evolving health policy landscape.

One major goal of the ACA is to expand coverage and increase access to care. Under the ACA, 20 million people have gained insurance coverage since $2010{ }^{19}$ The effects of coverage on access to healthcare are nuanced, but studies have shown improvements in access and services as a result of the ACA. ${ }^{19,20}$ The ACA exchanges currently face numerous hurdles, including changing regulations, lower-than-predicted enrollment, higher-risk enrollment, and uncertainty around costsharing reduction payments. The impact of uncertainty on the exchanges may result in barriers to health coverage and network challenges for providers, and may ultimately impact patient access to high-quality cancer care.

Section 1115 of the Social Security Act gives the Secretary of the Department of Health and Human Services the authority to approve demonstration projects requested by states to their Medicaid program. ${ }^{21}$ Section 1115 Medicaid demonstration waivers are used by states to implement changes to eligibility, benefits, and delivery systems, and frequently to create innovative Medicaid programming to provide greater coverage for patients. However, Medicaid waivers are increasingly being used to institute limitations and mandated activities for coverage, including work requirements, higher premiums, and coverage lock-out periods. These proposals may have significant implications for patients with cancer, who will likely be exempted from policies such as work requirements but will still need to navigate the associated paperwork requirements. As states harness greater authority over public and private health markets, health system stakeholders, including patients and providers, must be included as active participants in the policymaking process.

\section{Cancer Policy in 2018}

Congressman Mark DeSaulnier had just been sworn in as a member of the United States House of Representatives when he was diagnosed with chronic lymphocytic leukemia. Congressman Ted Poe had been serving for more than a decade when he received a diagnosis of leukemia in 2016. Together, Congressman DeSaulnier and Congressman Poe are working to shed light on the experience of Americans with cancer through the founding of the bipartisan Congressional Cancer Survivors Caucus. The Caucus brings together people affected by cancer to discuss how to create a future with even more survivors, providing an open forum to discuss policies, treatments, and opportunities to destigmatize cancer and improve communication between physicians and patients. ${ }^{22}$

The first policy initiative of the Caucus is the Cancer Care Planning and Communications (CCPC) Act introduced by Congressman Poe and Congressman DeSaulnier in 2018, during the 115th United States Congress. Care planning and coordination can lead to improved patient experience, but patients with cancer rarely receive a comprehensive care plan throughout the care continuum into survivorship and end of life. ${ }^{23}$ To improve the rate of cancer care planning and coordination, Congressman Poe and Congressman DeSaulnier are working to pass the CCPC Act, which would create a billing mechanism for cancer care planning and coordination in fee-for-service Medicaid. Speaking about the importance of the bill, Congressman DeSaulnier noted that "I learned when I was going through this that research shows that for the patient, or for family members, when you're first being diagnosed, you're retaining 1 in 4 words that are being communicated to you." ${ }^{24}$ Congressman Poe agreed with the importance of communication and care planning, stating, "We need to keep it simple for the patient. You have to have a plan, and somebody's got to be in charge, communicate that plan and inform it, and then have reimbursement, whether it's [from] Medicaid or Medicare, for a doctor's time to outline this plan. Communication is vital." 23

Congress is often criticized for partisanship, but Congressman Poe and Congressman DeSaulnier came together on the belief that cancer is not only a bipartisan issue but also a "nonpartisan" issue. ${ }^{23}$ Despite having different political backgrounds, the Congressmen agree on several issues relevant to cancer care, including support for increasing research funding and for preexisting condition protections in insurance coverage. ${ }^{23}$ The model proposed by Congressman Poe and Congressman DeSaulnier sets a hopeful tone for the future of cancer policy.

\section{Conclusions}

Innovation in cancer treatment has advanced rapidly in recent years, but shifting health policy combined with high drug prices and outdated reimbursement systems may create barriers to patient access to innovation. Stakeholders, including patients, providers, payers, regulators, and industry, must collaborate to find meaningful solutions to reimbursement, health coverage, and regulatory challenges in working toward a health system that facilitates patient access to high-quality cancer care and appropriate access to innovation.

Submitted December 4, 2018; accepted for publication January 4, 2019.

Disclosures: Ms. Schatz has disclosed that her spouse holds stock in TransEnterix, Array BioPharma, Editas Medicine, Amgen, Adamas Pharmaceuticals,

UnitedHealth, Intuitive Surgical, and Akers Biosciences. The remaining authors have disclosed that they have no financial interests, arrangements, affiliations, or commercial interests with the manufacturers of any products discussed in this article or their competitors.

Correspondence: Alyssa A. Schatz, MSW, National Comprehensive Cancer Network, 3025 Chemical Road, Suite 100, Plymouth Meeting, PA 19462 Email: schatz@nccn.org 


\section{References}

1. Gottlieb S. Accelerating access to innovation. Presented at the NCCN Policy Summit: Policy Strategies for the "New Normal" in Healthcare to Ensure Access to High-Quality Cancer Care; June 25, 2018; Washington, DC.

2. Beaver JA, Howie LJ, Pelosof L, et al. A 25-year experience of US Food and Drug Administration accelerated approval of malignant hematology and oncology drugs and biologics: a review. JAMA Oncol 2018;4: 849-856.

3. Sparano JA, Gray RJ, Wood WC, et al. TAILORx: phase III trial of chemoendocrine therapy versus endocrine therapy alone in hormone receptor-positive, HER2-negative, node-negative breast cancer and an intermediate prognosis 21-gene recurrence score [abstract]. J Clin Oncol 2018;36(Suppl):Abstract LBA1.

4. Regulatory Barriers Impair Alignment of Biopharmaceutical Price and Value. National Pharmaceutical Council website. Available at: https://www. npcnow.org/publication/regulatory-barriers-impair-alignmentbiopharmaceutical-price-and-value. Accessed September 21, 2018.

5. Issue Brief: Value-Based Pricing for Pharmaceuticals: Implications of the Shift From Volume to Value. Deloitte Center for Health Solutions website. Available at: https://deloitte.wsj.com/cfo/files/2012/09/ ValueBasedPricingPharma.pdf. Accessed August 31, 2018.

6. Kline R. Paying for innovation. Panel discussion at the NCCN Policy Summit: Policy Strategies for the "New Normal" in Healthcare to Ensure Access to High-Quality Cancer Care; June 25, 2018; Washington, DC.

7. Coverage With Evidence Development. Centers for Medicare and Medicaid Services website. Available at: https://www.cms.gov/Medicare/ Coverage/Coverage-with-Evidence-Development/index.html. Accessed August 31, 2018.

8. Farnia S. Paying for innovation. Panel discussion at the NCCN Policy Summit: Policy Strategies for the "New Normal" in Healthcare to Ensure Access to High Quality Cancer Care; June 25, 2018; Washington, DC.

9. Gutierrez M. Paying for innovation. Panel discussion at the NCCN Policy Summit: Policy Strategies for the "New Normal" in Healthcare to Ensure Access to High-Quality Cancer Care; June 25, 2018; Washington, DC.

10. Hirsch BR, Califf RM, Cheng SK, et al. Characteristics of oncology clinical trials: insights from a systematic analysis of ClinicalTrials.gov. JAMA Intern Med 2013;173:972-979.

11. Joho S. Paying for Innovation. Panel discussion at the NCCN Policy Summit: Policy Strategies for the "New Normal" in Healthcare to Ensure Access to High Quality Cancer Care; June 25, 2018; Washington, DC.

12. The Evolving Healthcare Landscape: Implications for Access to Quality Cancer Care. Panel Discussion at the NCCN Policy Summit: Policy Strategies for the "New Normal" in Healthcare to Ensure Access to High Quality Cancer Care; June 25, 2018; Washington DC.
13. Schatz A. Network adequacy in the ACA exchange: narrow network implications for access to high quality academic cancer centers. Presented at the NCCN Policy Summit: Policy Strategies for the "New Normal" in Healthcare to Ensure Access to High-Quality Cancer Care; Washington, DC; June 25, 2018.

14. Schatz A, Winckworth-Prejsnar K. Survey of NCl-designated cancer centers finds most are out-of-network on exchanges. Am J Manag Care 2018;24 SP517-518.

15. Corlette S, Volk J, Berenson RA. Narrow Provider Networks in New Health Plans: Balancing Affordability With Access to Quality Care. Urban Institute website. Available at: urban.org/research/publication/narrow-providernetworks-new-health-plans. Accessed August 13, 2018.

16. Avalere Health LLC. Network Design: Trends in Tiered and Narrow Insurance Networks. Available at: avalere-health-production.s3.amazonaws. com/uploads/pdfs/1444082614_AH_Tiered_Network_White_Paper_v3. pdf. Accessed August 3, 2018

17. Smith A. On the Road to Recovery: Traveling for Cancer Treatment. Cure website. Available at: curetoday.com/publications/cure/2016/winter2016/on-the-road-to-recovery-traveling-for-cancer-treatment. Accessed August 3, 2018

18. Health Insurance Coverage and the Affordable Care Act, 2010-2016. ASPE website. Available at: https://aspe.hhs.gov/pdf-report/healthinsurance-coverage-and-affordable-care-act-2010-2016. Published July 16, 2016. Accessed September 1, 2017.

19. McMorrow S, Polsky D. Insurance Coverage and Access to Care Under the Affordable Care Act. Penn LDI website. Available at: https://ldi.upenn. edu/brief/insurance-coverage-and-access-care-under-affordable-careact. Accessed September 5, 2018.

20. Glied SA, Ma S, Borja A. Effect of the Affordable Care Act on Health Care Access. The Commonwealth Fund website. Available at: https://www. commonwealthfund.org/publications/issue-briefs/2017/may/effectaffordable-care-act-health-care-access. Accessed September 4, 2018.

21. About Section 1115 Demonstrations. Medicaid.gov. Available at: https:// www.medicaid.gov/medicaid/section-1115-demo/about-1115/index. html. Accessed September 5, 2018

22. DeSaulnier M. Join the Congressional Cancer Survivors Caucus DearColleague.us website. http://dearcolleague.us/2017/12/join-thecongressional-cancer-survivors-caucus-3/. Accessed August 31, 2018.

23. Ganz PA, Casillas J, Hahn EE. Ensuring quality care for cancer survivors: implementing the survivorship care plan. Semin Oncol Nurs 2008;24: 208-217.

24. DeSaulnier M, Poe T. Cancer Policy in 2018. Presented at the NCCN Policy Summit: Policy Strategies for the "New Normal" in Healthcare to Ensure Access to High Quality Cancer Care; June 25, 2018; Washington, DC. 